Giuseppe Lauria, MD

Patrizia Dacci, MD, PhD

Raffaella Lombardi, PhD

Daniele Cazzato, MD

Carla Porretta-Serapiglia,

$\mathrm{PhD}$

Michela Taiana, PhD

Jenny Sassone, PhD

Eleonora Dalla Bella, MD

Sara Rinaldo, Tch

Christian Lettieri, MD

Roberto Eleopra, MD

Grazia Devigili, MD, $\mathrm{PhD}$

Correspondence to

Dr. Lauria:

glauria@istituto-besta.it

Supplemental data at Neurology.org

\title{
Side and time variability of intraepidermal nerve fiber density
}

\section{ABSTRACT}

Objective: To assess the right-to-left and short-term variability of intraepidermal nerve fiber density (IENFD) at the distal site of the leg.

Methods: Patients with possible or probable small fiber neuropathy (SFN) and healthy volunteers $(\mathrm{HV}$ s) underwent skin biopsies at the right and left distal leg. A subgroup of participants underwent follow-up biopsies 20 days later. Biopsies were immunostained by polyclonal anti-protein gene product 9.5 antibodies, and IENFD was quantified in nonconsecutive sections following published guidelines by operators blinded to the participants' condition (diagnosis, side, and time of biopsy). Findings were referred to sex- and age-adjusted normative values.

Results: Forty patients and $17 \mathrm{HVs}$ underwent bilateral skin biopsies; 15 patients and $8 \mathrm{HVs}$ underwent follow-up skin biopsies. Sural nerve and dorsal sural nerve conduction studies were normal in all participants. Interside IENFD did not differ both in patients (median 2.45 IENF/ $\mathrm{mm} \pm 1.45 \mathrm{SD}$ right; $2.2 \mathrm{IENF} / \mathrm{mm} \pm 1.32 \mathrm{SD}$ left) and $\mathrm{HVs}$ (median $6.3 \mathrm{IENF} / \mathrm{mm} \pm 2.81$ right; $6.2 \mathrm{IENF} / \mathrm{mm} \pm 2.3 \mathrm{SD}$ left). The right-to-left correlation coefficients were excellent (Pearson 0.95 in SFN and 0.97 in HVs). The analysis of IENFD at 20-day follow-up biopsy showed no difference between sides in both groups and yielded excellent correlation coefficients.

Conclusions: The diagnosis of SFN can be reliably ascertained by unilateral skin biopsy at the distal site of the leg, and IENFD is not expected to vary within 3 weeks. Neurology ${ }^{\circledR} 2015 ; 84: 2368-2371$

\section{GLOSSARY}

HV = healthy volunteer; IENF = intraepidermal nerve fiber; IENFD = intraepidermal nerve fiber density; $\mathbf{S F N}=$ small fiber neuropathy.

Intraepidermal nerve fiber density (IENFD) at the distal site of the leg is a widely used tool to confirm the diagnosis of small fiber neuropathy (SFN). ${ }^{1}$ The availability of age- and sex-adjusted reference values has improved the reliability of the method based on bright-field immunohistochemistry. ${ }^{2}$ Skin biopsy, like electrodiagnostic studies, is usually performed unilaterally, and no recommendation currently exists to perform it on the right or left side for diagnosing SFN. However, while the right-to-left concordance of sural nerve conduction velocity and amplitude has been investigated in patients with neuropathy and healthy volunteers (HVs), ${ }^{3}$ it is unknown whether this variable can affect the diagnostic performance of skin biopsy. One further variable is the consistency of IENFD over a short period of time. Skin is a self-renewal tissue, and the epidermis has an active turnover estimated at about 40 days. ${ }^{4}$ The loss of IENF, which is the hallmark of SFN, can modify the architecture of the epidermis and possibly of keratinocyte functioning, which are part of the complex peripheral network involved in thermal sensation and nociception. ${ }^{5}$ It is unknown whether epidermis turnover can influence IENFD in neuropathy and HVs. Our study aimed at addressing the right-to-left and time variability of IENFD over a period of 20 days, namely, the estimated half-life for the complete epidermis renewal, in patients with SFN and HVs. Our results strengthen the robustness of skin biopsy in diagnosing SFN and support its use as a biomarker in clinical trials.

\footnotetext{
From the 3rd Neurology Unit and Skin Biopsy (G.L., P.D., R.L., D.C., C.P.-S., M.T., J.S., E.D.B.), Peripheral Neuropathy and Neuropathic Pain Clinic, IRCCS Foundation Carlo Besta Neurological Institute, Milan; and Neurological Unit (S.R., C.L., R.E., G.D.), University Hospital S. Maria della Misericordia, Udine, Italy.

Go to Neurology.org for full disclosures. Funding information and disclosures deemed relevant by the authors, if any, are provided at the end of the article.
} 
METHODS Consecutive patients referred for a skin biopsy to confirm the diagnosis of possible or probable symmetric SFN according to published criteria ${ }^{6}$ were enrolled. All patients underwent a thorough screening for known causes of SFN. HVs recruited among hospital employers and patients' relatives were asked to participate. Inclusion criteria for HVs were no symptoms or risk factors for neuropathy and a normal neurologic examination. Exclusion criteria for both groups were anticoagulant treatment, known bleeding disorders, and local skin infections. All participants underwent skin biopsies at the right and left distal leg, $10 \mathrm{~cm}$ above the external malleolus within the territory of the sural nerve. A subgroup of participants was asked to undergo follow-up biopsies 20 days later 2 to $3 \mathrm{~mm}$ apart from the scar of the prior biopsy. All biopsies were taken using a disposable $3-\mathrm{mm}$ punch, under sterile technique, and after topical anesthesia with spray ice. No suture was needed.
The immunostaining procedure was performed following published guidelines using polyclonal anti-protein gene product 9.5 antibodies (UltraClone Ltd., Isle of Wight, UK). ${ }^{1}$ Briefly, specimens were fixed (2\% paraformaldehydelysine-sodium periodate, $4^{\circ} \mathrm{C}$ overnight), cryoprotected, and serially cut with a cryostat. Each 3-mm punch biopsy yielded about 45 vertical $50-\mu \mathrm{m}$ sections. To decrease the variability of section length, IENFD was quantified on 3 nonconsecutive central sections (e.g., no. 25, 27, 29). All fibers crossing the dermal-epidermal junction, excluding fragments and secondary branching, were counted and their number was divided by the length of the epidermis to obtain a linear density $(\mathrm{IENF} / \mathrm{mm})$. Counts were performed by 2 expert operators blinded to conditions (diagnosis, side, and time of biopsy). IENFD was compared with sex- and age-adjusted normative values. ${ }^{2}$

\begin{tabular}{|c|c|c|c|c|c|c|c|c|}
\hline Table 1 & $\begin{array}{l}\text { emogra } \\
\text { alues at }\end{array}$ & the $\mathrm{fc}_{\mathrm{c}}$ & $\begin{array}{l}\text { lata and IE } \\
\text { llow-up ski }\end{array}$ & $\begin{array}{l}\text { NFD values a } \\
\text { n biopsy perf }\end{array}$ & $\begin{array}{l}\text { the right and lef } \\
\text { ormed at } 20 \text { days }\end{array}$ & $\begin{array}{l}\text { distal site } \\
\text { n patients n }\end{array}$ & $\begin{array}{l}\text { ff the leg and cor } \\
\text { ith SFN and heal }\end{array}$ & $\begin{array}{l}\text { responding } \\
\text { hy volunteers }\end{array}$ \\
\hline Participant no. & Age, y & Sex & Diagnosis & Right IENFD & Right IENFD $20 \mathrm{~d}$ & Left IENFD & Left IENFD $20 \mathrm{~d}$ & 5th percentile \\
\hline 2 & 32 & M & SFN & 3.5 & 3.8 & ND & ND & ND \\
\hline 22 & 59 & M & SFN & 1.7 & 1.9 & 1.6 & 1.6 & 3.5 \\
\hline 23 & 24 & $\mathrm{~F}$ & SFN & 2.7 & 2.7 & ND & ND & 8.4 \\
\hline 26 & 41 & $M$ & SFN & 2.2 & 2.1 & 2.1 & 2.1 & 4.4 \\
\hline 27 & 46 & M & SFN & 3.2 & 2.9 & 3.3 & 2.7 & 4.4 \\
\hline 28 & 52 & $\mathrm{~F}$ & SFN & 2.1 & 2.2 & 2.3 & 2.1 & 4.3 \\
\hline 29 & 61 & $\mathrm{~F}$ & SFN & 1.1 & 1.2 & 1.2 & 1.0 & 3.2 \\
\hline 30 & 22 & $\mathrm{~F}$ & SFN & 2.5 & 2.4 & ND & ND & 8.4 \\
\hline 31 & 59 & M & SFN & 1.6 & 1.7 & ND & ND & 3.5 \\
\hline 33 & 44 & M & SFN & 1.5 & 1.6 & 1.3 & 1.3 & 4.4 \\
\hline 34 & 73 & M & SFN & 1.2 & 1.3 & 1.4 & 1.4 & 2.1 \\
\hline 35 & 79 & M & SFN & 1.5 & 1.6 & 1.8 & 1.8 & 2.1 \\
\hline 36 & 49 & $\mathrm{~F}$ & SFN & 2.1 & 2.0 & 2.2 & 2.1 & 5.7 \\
\hline 37 & 38 & $\mathrm{~F}$ & SFN & 0.8 & 1.0 & 0.8 & 1.2 & 7.1 \\
\hline Mean & & & & 2.0 & 2.0 & 1.8 & 1.7 & - \\
\hline Median & & & & 1.9 & 2.0 & 1.7 & 1.7 & - \\
\hline SD & & & & 0.8 & 0.7 & 0.7 & 0.5 & - \\
\hline Pearson & & & & 0.98 & & 0.96 & & - \\
\hline 45 & 63 & M & Healthy & 3.6 & 3.8 & ND & ND & 2.8 \\
\hline 46 & 75 & F & Healthy & 11.6 & 11.2 & 8.9 & 9.0 & 2.2 \\
\hline 47 & 72 & M & Healthy & 3.8 & 3.4 & ND & ND & 2.1 \\
\hline 50 & 75 & M & Healthy & 4.2 & 3.9 & ND & ND & 2.1 \\
\hline 52 & 44 & M & Healthy & 6.8 & 6.5 & 6.5 & 5.8 & 4.4 \\
\hline 56 & 70 & M & Healthy & 3.5 & 3.6 & 3.3 & 3.6 & 2.1 \\
\hline 54 & 51 & $\mathrm{~F}$ & Healthy & 3.8 & 3.5 & 3.8 & 3.3 & 4.3 \\
\hline 57 & 58 & $\mathrm{~F}$ & Healthy & 6.3 & 6.2 & 6.2 & 6.0 & 4.3 \\
\hline Mean & & & & 5.5 & 5.3 & 5.7 & 5.5 & - \\
\hline Median & & & & 4.0 & 3.9 & 6.2 & 5.8 & - \\
\hline SD & & & & 2.8 & 2.7 & 2.3 & 2.3 & - \\
\hline \multicolumn{4}{|l|}{ Pearson } & 1.00 & & 0.98 & & - \\
\hline
\end{tabular}

Abbreviations: IENFD = intraepidermal nerve fiber density; ND = not done; SFN = small fiber neuropathy.

Participants' number corresponds to that of table e-1. 


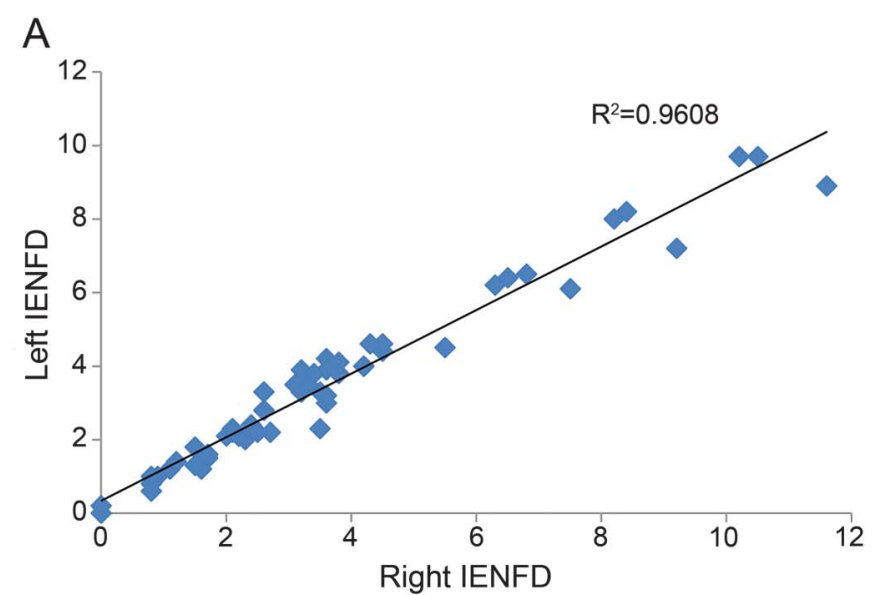

B

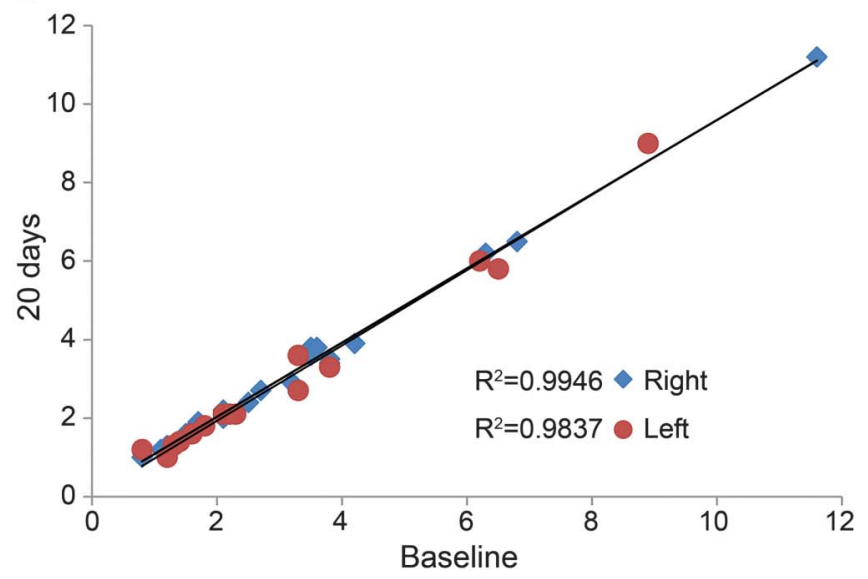

Linear regression analyses demonstrating the excellent right-to-left correlation of intraepidermal nerve fiber density (IENFD) in (A) 40 patients with small fiber neuropathy and 17 healthy volunteers, and (B) between baseline and 20-day follow-up biopsy on both sides in 15 patients with small fiber neuropathy and 8 healthy volunteers.

Standard protocol approvals, registrations, and patient consents. The study was approved by the local ethic committees, and each participant was enrolled after giving written informed consent.

Statistical analysis. Data were presented using descriptive statistics, and comparison between groups was performed using parametric or nonparametric statistics where appropriate. Analyses were conducted using the Stata 9 software (StataCorp, College Station, TX).

RESULTS Forty eligible patients and 17 HVs were enrolled, and skin biopsy was performed bilaterally (table e-1 on the Neurology ${ }^{\circledR}$ Web site at Neurology.org). Fifteen patients with SFN and 8 HVs underwent follow-up biopsies (bilaterally in 11 and 5, respectively) (table 1). Patients did not report any change of symptoms between baseline and follow-up biopsy, and the neurologic examination was unchanged. At baseline, all patients with SFN and $\mathrm{HVs}$ showed normal sural nerve action potential amplitudes bilaterally $(>10 \mu \mathrm{V}$ in those younger than 60 years and $>6 \mu \mathrm{V}$ in those
60 years and older). Dorsal sural nerve action potential was recorded in 11 patients with SFN and $6 \mathrm{HVs}$, showing normal amplitude $(>2.5 \mu \mathrm{V})$ and mean sural nerve action potential/dorsal sural nerve action potential ratio $(>3){ }^{7}$

In patients with SFN, mean and median IENFD values were $2.45 \mathrm{IENF} / \mathrm{mm}$ and $2.3 \mathrm{IENF} / \mathrm{mm} \pm$ $1.45 \mathrm{SD}$ at the right side, and $2.4 \mathrm{IENF} / \mathrm{mm}$ and 2.2 $\mathrm{IENF} / \mathrm{mm} \pm 1.32 \mathrm{SD}$ at the left side, a nonsignificant difference. In 35 of 40 patients, IENFD was bilaterally below the fifth percentile. Among the remaining patients, only 2 (no. 15 and 18; idiopathic SFN) had IENFD bilaterally about 30\% higher than the cutoff, thus not confirming the diagnosis of SFN pathologically, whereas the others (no. 4, 9, 10) showed values at the cutoff, making the diagnosis possible pathologically. In $\mathrm{HV}_{\mathrm{s}}$, mean and median values of IENFD were $6.38 \mathrm{IENF} / \mathrm{mm}$ and 6.3 $\mathrm{IENF} / \mathrm{mm} \pm 2.81 \mathrm{SD}$ at the right side, and 6.0 $\mathrm{IENF} / \mathrm{mm}$ and $6.2 \mathrm{IENF} / \mathrm{mm} \pm 2.3 \mathrm{SD}$ at the left side, a nonsignificant difference. In 15 of $17 \mathrm{HVs}$, IENFD was bilaterally above the fifth percentile. Of the remaining $2 \mathrm{HVs}$, one (no. 54) had IENFD about $10 \%$ lower than the cutoff, whereas the other (no. 53) had IENFD at the cutoff (table e-1). The right-to-left correlation of IENFD computed for all participants was excellent (figure). The correlation analysis between IENFD at baseline and 20-day follow-up was performed in 15 patients with SFN and $8 \mathrm{HVs}$ (table 1). Mean and median values did not differ between sides and the linear regression analysis yielded an excellent correlation (figure).

DISCUSSION Skin biopsy performed using a 3-mm disposable punch is safe and minimally invasive, with minor side effects in $<2 / 1,000$ individuals. ${ }^{1}$ It can be easily repeated in the same area for follow-up studies because of the lack of IENFD variability between counts obtained from close biopsies in the same sensory nerve territory. ${ }^{8}$ However, the variability of IENFD between the right and left distal leg and within a 20-day frame, which is the half-time of epidermis renewal, has not been investigated to date. We demonstrate that the value of IENFD is independent of the side where biopsy is performed and, likely, epidermis turnover. If IENFD was affected by the turnover of keratinocytes, a follow-up biopsy at their half-life of renewal should have captured any related change. In the absence of any factor that can vary IENFD, such as neuropathy progression, biopsy in a different sensory nerve territory, technical issues in biopsy processing section, and number of sections quantified, ${ }^{9}$ any significant change would be attributed to intrinsic skin variables. Since we used the bright-field method and not indirect immunofluorescence, ${ }^{10}$ we 
did not reassess intra- and interobserver agreement on IENFD quantification, knowing its excellent results have already been published. ${ }^{1}$

Our results, showing overlapping values and excellent correlation coefficients for IENFD quantification both in HVs and patients with SFN, confirmed that skin biopsy can be performed unilaterally to assess the diagnosis of SFN in individual patients and that IENFD can be reliably used as a biomarker of small nerve fiber degeneration within a 3-week period. These findings can strengthen the use of skin biopsy also as outcome measure in clinical trials.

\section{AUTHOR CONTRIBUTIONS}

Giuseppe Lauria designed the study, performed the statistical analysis, and wrote the manuscript. Patrizia Dacci, Daniele Cazzato, Eleonora Dalla Bella, Christian Lettieri, Roberto Eleopra, Grazia Devigili recruited patients and healthy controls, performed the diagnostic assessment, performed skin biopsies, and read, edited, and approved the manuscript. Raffaella Lombardi, Sara Rinaldo, Carla PorrettaSerapiglia, Michela Taiana, Jenny Sassone performed skin biopsy processing and nerve fiber quantification, and read, edited, and approved the manuscript.

\section{STUDY FUNDING}

The study was financed by institutional funding (IRCCS Foundation Carlo Besta Neurological Institute, Ricerca Corrente, Italian Ministry of Health) and the European Union 7th Framework Programme (grant 602273).

\section{DISCLOSURE}

The authors report no disclosures relevant to the manuscript. Go to Neurology.org for full disclosures.

Received December 20, 2014. Accepted in final form February 26, 2015.

\section{REFERENCES}

1. Lauria G, Hsieh ST, Johansson O, et al. European Federation of Neurological Societies/Peripheral Nerve Society Guideline on the use of skin biopsy in the diagnosis of small fiber neuropathy. J Peripher Nerv Syst 2010;15: 79-92.

2. Lauria G, Bakkers M, Schmitz C, et al. Intraepidermal nerve fiber density at the distal leg: a worldwide normative reference study. J Peripher Nerv Syst 2010;15:202-207.

3. Perkins BA, Ngo M, Bril V. Symmetry of nerve conduction studies in different stages of diabetic polyneuropathy. Muscle Nerve 2002;25:212-217.

4. Hoath SB, Leahy DG. The organization of human epidermis: functional epidermal units and phi proportionality. J Invest Dermatol 2003;121:1440-1446.

5. Lumpkin EA, Caterina MJ. Mechanisms of sensory transduction in the skin. Nature 2007;445:858-865.

6. Tesfaye S, Boulton AJ, Dyck PJ, et al. Diabetic neuropathies: update on definitions, diagnostic criteria, estimation of severity, and treatments. Diabetes Care 2010;33: 2285-2293.

7. Frigeni B, Cacciavillani M, Ermani M, et al. Neurophysiological examination of dorsal sural nerve. Muscle Nerve 2012;46:895-898.

8. McArthur JC, Stocks EA, Hauer P, Cornblath DR, Griffin JW. Epidermal nerve fiber density: normative reference range and diagnostic efficiency. Arch Neurol 1998; 55:1513-1520.

9. Engelstad JK, Taylor SW, Witt LV, et al. Epidermal nerve fibers: confidence intervals and continuous measures with nerve conduction. Neurology 2012;79:2187-2193.

10. Wopking S, Scherens A, Haussleiter IS, et al. Significant difference between three observers in the assessment of intraepidermal nerve fiber density in skin biopsy. BMC Neurol 2009;9:13.

\section{Neurology ${ }^{\circledR}$ Genetics Call For Papers}

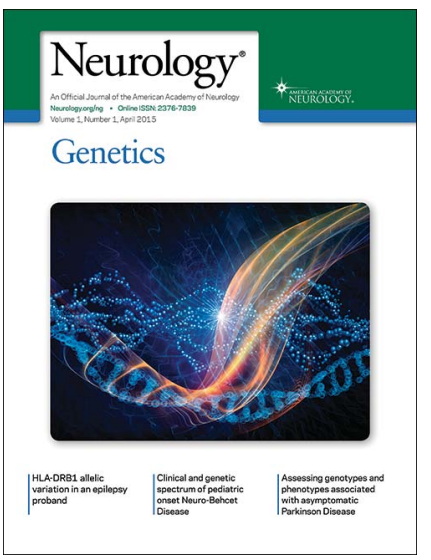

Neurology: Genetics is an open access, online only journal that will provide neurologists with outstanding original contributions that elucidate the role of genetic and epigenetic variation in diseases and biological traits of the central and peripheral nervous system. We welcome all submissions. For more information on how to submit, visit http://www.neurology.org/site/ gen/gen2.xhtml. 


\section{Neurology}

\section{Side and time variability of intraepidermal nerve fiber density}

Giuseppe Lauria, Patrizia Dacci, Raffaella Lombardi, et al. Neurology 2015;84;2368-2371 Published Online before print May 13, 2015

DOI 10.1212/WNL.0000000000001666

\section{This information is current as of May 13, 2015}

\section{Updated Information \& Services}

Supplementary Material

\section{References}

Citations

Subspecialty Collections

Permissions \& Licensing

Reprints including high resolution figures, can be found at: http://www.neurology.org/content/84/23/2368.full.html

Supplementary material can be found at: http://www.neurology.org/content/suppl/2015/05/13/WNL.0000000000 001666.DC1

This article cites 10 articles, 2 of which you can access for free at: http://www.neurology.org/content/84/23/2368.full.html\#\#ref-list-1

This article has been cited by 1 HighWire-hosted articles: http://www.neurology.org/content/84/23/2368.full.html\#\#otherarticles

This article, along with others on similar topics, appears in the following collection(s):

Neuropathic pain

http://www.neurology.org//cgi/collection/neuropathic_pain Peripheral neuropathy http://www.neurology.org//cgi/collection/peripheral_neuropathy

Information about reproducing this article in parts (figures,tables) or in its entirety can be found online at: http://www.neurology.org/misc/about.xhtml\#permissions

Information about ordering reprints can be found online: http://www.neurology.org/misc/addir.xhtml\#reprintsus

Neurology ${ }^{\circledR}$ is the official journal of the American Academy of Neurology. Published continuously since 1951, it is now a weekly with 48 issues per year. Copyright @ 2015 American Academy of Neurology. All rights reserved. Print ISSN: 0028-3878. Online ISSN: 1526-632X.

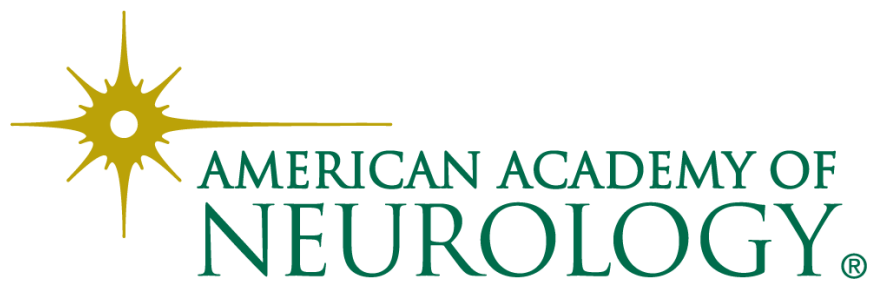

